\title{
Saúde é política... Há uma grande desordem sob o céu: a experiência "comunal" do 150 Congresso Paulista de Saúde Pública
}

\section{Health is politics... There is a great disorder under heaven: the "communal" experience of the $15^{\text {th }}$ Congresso Paulista de Saúde Pública}

\author{
Carlos Botazzo \\ Universidade de São Paulo. Faculdade de Saúde Pública. São \\ Paulo, SP, Brasil. \\ E-mail: botazzoœusp.br

\section{Marília Cristina Prado Louvison} \\ Universidade de São Paulo. Faculdade de Saúde Pública. São \\ Paulo, SP, Brasil. \\ E-mail: mariliacpløusp.br
}

\section{Marco Akerman}

Universidade de São Paulo. Faculdade de Saúde Pública. São Paulo, SP, Brasil.

E-mail: marco.akermanळgmail.com

\section{Ana Lúcia Pereira}

Universidade Federal de São Paulo. Escola Paulista de Medicina. Departamento de Medicina Preventiva. São Paulo, SP, Brasil.

E-mail: ana.pereiraog®unifesp.br

\section{José Alexandre Buso Weiller}

Universidade de São Paulo. Faculdade de Saúde Pública. São Paulo, SP, Brasil.

E-mail: josealexandre.bwळgmail.com

\section{Ricardo Rodrigues Teixeira}

Universidade de São Paulo. Faculdade de Medicina. São Paulo, SP, Brasil.

E-mail: ricarteळusp.br

\section{Resumo}

Este texto tem por finalidade apresentar um breve relato das atividades preparatórias do $15^{\circ}$ Congresso Paulista de Saúde Pública, realizado no segundo semestre de 2017. No material utilizado, estavam inclusas notas tomadas durante as reuniões preparatórias, trechos de mensagens trocadas e, fundamentalmente, o registro vivo contido na memória dos autores, enquanto participantes do processo de organização. Apresentamos, então, os contornos da necessária politização da saúde e as principais tendências observadas nas atividades desenvolvidas em todos os núcleos regionais da Associação Paulista de Saúde Pública. É realçada, ademais, a particularidade do congresso, que mostrou forte inovação na proposta de programa; foi um congresso desconstruído, em movimento, que contou com a realização de nove eventos nas regiões que sediam núcleos da associação. 0 décimo evento, realizado como atividade de finalização, ocorreu em São Paulo na forma de celebração teóricopolítica. Ao final, destacamos o fortalecimento dos laços associativos e a consolidação da organização em núcleos.

Palavras-chave: Saúde Coletiva; Associação; Saúde e Sociedade; Política; Movimentos Sociais.

\section{Correspondência}




\section{Abstract}

This text aims to present a brief account of the preparatory activities of the $15^{\text {th }}$ Congresso Paulista de Saúde Pública, held in the second half of 2017. Within the material that was used, there are notes taken during the preparatory meetings, excerpts from the exchanged messages and, fundamentally, the living record contained in the memory of the authors, as participants in the organization process. We present then the contours of the necessary health politicization and the trends that were mainly observed in the activities carried out in all the regional centers of the Associação Paulista de Saúde Pública. It was also highlighted the particularity of the congress, which presented a very innovative program proposal; it was a forward-looking propulsive congress, composed by nine events hosted in the regions in which are located the association centers. The $10^{\text {th }}$ event (a closing activity) took place in São Paulo as a theoretical-political celebration. At last, we highlight the strengthening of associative ties and the consolidation of the organization into nuclei.

Keywords: Public Health; Association; Health and Society; Politics; Social Movements.
Fazer um relato, como um pós-diário, de um evento tão rico e generoso como foi $015^{\circ}$ Congresso Paulista de Saúde Pública não é coisa trivial, e só podemos fazê-lo de maneira circunstanciada. É preciso cautela, pois um relato mais bem organizado - uma verdadeira memorialística - ainda precisa ser feito, porém, tal trabalho só poderá ser realizado em conjunto, pelas muitas pessoas que participaram da construção do próprio congresso, integrando o coletivo organizador que deu movimento e forma ao novo projeto.

Neste sentido, partilhamos extensamente a leitura de Aurea Ianni, quando antes, no artigo onde refletiu sobre a realização do $13^{\circ}$ Congresso, admitiu a complexidade da empreitada. "Tarefa difícil”, escreveu ela,

pois não se trata de um evento que tem por base algumas teses claramente formuladas, apresentadas e debatidas. Os congressos paulistas são eventos em que as teses, ainda que presentes, transcorrem de forma mais solta, fluida, menos definidas e demarcadas do que nas conferências de saúde, por exemplo; em que as múltiplas permeabilidades são transpassadas entre si, produzindo resultados outros, diversos, inesperados e esperados, conclusivos e abertos, similares e diferentes. (Ianni, 2015, p. 14, grifo nosso)

Assim ocorreu também com o $15^{\circ}$ Congresso, um evento permeável, múltiplo, no território, mutante, em movimento, aberto ao mundo, cujas "múltiplas permeabilidades" se produziam à medida que ia sendo formulado, um devir que se configurava no extenso processo da sua realização, causando incômodos e alguma perplexidade a tantos interlocutores que viam os esboços ainda descosidos do projeto: "como assim, em movimento?! No território?! Mas as atividades nos núcleos são etapas regionais ou pré-congressos? Vai ter uma comissão organizadora central e outras locais? Afinal, quantas comissões vamos ter que organizar? Se não temos financiamento, como vamos fazer? Há uma grande desordem sob o céu, o que isso quer dizer? Que coisa depressiva!". Ensaiemos, portanto, esta memória ex post. Buscaremos organizar os principais elementos do percurso que vivemos 
coletivamente entre novembro de 2016 e novembro de 2017, quando foi finalizado formalmente o congresso na Apoteose. Para este propósito, usaremos notas de reuniões, fragmentos de troca de correspondência pela internet e aplicativos de redes sociais e, naturalmente, o que está contido na nossa própria lembrança como participantes diretos no processo.

\section{Um pouco das circunstâncias que nos conduziram ao $15^{\circ}$ Congresso}

Os acontecidos nesta $15^{\text {a }}$ edição do congresso guardam relação com as edições anteriores, sobretudo a $13^{\mathrm{a}}$ (2013) e a $14^{\circ}$ (2015), porém é possível localizar a viragem na perspectiva política da Associação Paulista de Saúde Pública (APSP) no seminário realizado em março de 2016, cuja finalidade explícita foi planejar o trabalho político da entidade na gestão 2015-2017 (a diretoria havia sido reeleita em setembro de 2015, no $14^{\circ}$ Congresso, realizado em São Carlos, tendo a posse ocorrido em dezembro daquele ano).

Assim, quando houve o seminário de março de 2016, o escopo era justamente preparar-se para o biênio que começava. Naquela altura, a crise institucional no Brasil caminhava a passos largos para o impeachment da presidente Dilma Rousseff, aceito pela Câmara dos Deputados em 2 de dezembro de 2015. A conjuntura apontava para o agravamento da crise política iniciada em 2014, num evidente processo de violação constitucional, mas esta perspectiva ainda não estava de todo clara. De um lado, havia consternação com os eventos políticos que afloravam; em geral, a reiteração cotidiana de teses alinhavadas pelos setores conservadores da sociedade e amplificadas pelo oligopólio dos meios de comunicação, os quais, junto com amplos setores do Judiciário, tiveram papel de protagonismo em todas as ocorrências daquele momento e no período que se seguiu, até o presente. Por outro lado, havia a tendência de minimizar os eventos nacionais e situálos como parte do processo mundial de avanço do neoliberalismo, porém sem consequências maiores entre nós do que o observado na década anterior, pois os germes desse avanço, diziam, já se faziam presentes mesmo durante os governos populares, fosse em termos de políticas sociais - direitos e garantias securitárias (saúde incluída), direitos das "minorias" etc. - fosse em termos de políticas públicas amplas, como a da autonomia da universidade, da gestão da economia, da salvaguarda dos recursos naturais e do meio ambiente, enfim, do financiamento do Estado e das relações entre os interesses nacionais versus os interesses privados, sobremaneira os do capital financeiro. Ou seja, ou bem se amplificava a percepção da crise que batia às portas ou tal crise aparecia de forma tímida, ainda carecendo de maiores explicações sociológicas.

Por estes motivos, não deixou de ser curioso o posicionamento do seminário então realizado. Houve claro apoio a um posicionamento político mais explícito da APSP em defesa das conquistas democráticas desde a Reforma Sanitária e do processo constituinte de 1988, do sistema público de saúde, da universidade aberta e plural e dos direitos sociais e políticos de todos os cidadãos. Pois, se em conjunto não expressavam o mesmo nível de preocupação com os rumos que a política geral vinha tomando, os presentes manifestaram seu firme compromisso com a democracia, desejando colocar os projetos associativos neste rumo, inquestionavelmente. $\mathrm{E}$ as falas coincidiram todas em afirmar a necessidade de radicalizar a perspectiva política e a busca de alianças com movimentos sociais e sindicatos, ao tempo que se definia a perspectiva, também radical, de luta por um sistema público e universal de saúde.

As notas da reunião apontam claramente para o que então foi denominado de "uma pauta estratégica para a APSP”: desnaturalizar o social; atuar na defesa das políticas públicas e dos direitos universais; pensar a produção do comum; retornar ao mundo do trabalhador e do trabalho, pensar criticamente a dinâmica do capitalismo hoje; buscar diálogos e alianças em aproximação com os movimentos sociais, sindicatos e o grupo dos médicos populares; pensar a realização de projetos coletivos, ativando os diferentes grupos já constituídos, como o fórum de formação, direitos e saúde mental, gênero e raça, memória da saúde etc.

Se pudesse haver alguma dúvida quanto à expressão do político no ativismo sanitário paulista em 2016 e 2017, este seminário foi definitivamente a afirmação da política e, intuitivamente, dos rumos que o futuro congresso tomaria. Na ocasião, a saúde 
já aparecia claramente como expressão da política, e já se pensava com nitidez haver desordem sob o céu...

Ao longo de 2016 as coisas só iriam piorar, as violações de direitos só fizeram aumentar: a "desordem sob o céu", como anomia, tornava-se cada vez mais evidente. Vitorioso o golpe parlamentarmidiático-jurídico, passamos a assistir ao rápido desmonte de políticas sociais e ao encurtamento da dimensão pública da existência. Não apenas isso, pois manifestações de extrema direita, com ataques à democracia e à liberdade de expressão, passaram a fazer parte do cotidiano. No final de 2016, a sensação de que havíamos mergulhado na escuridão tornou-se palpável, uma sensação globosa colando nos nossos corpos e mentes.

\section{Um brainstorming performático}

Foi nesta conjuntura que se realizou a primeira reunião de organização do $15^{\circ}$ Congresso. Reuniões científicas de natureza associativa são preparadas com bastante antecedência, em geral com prazo não inferior a um ano. Quando o objeto da reunião é percebido, como diria Donnangelo (1983, p. 19), "estável e pouco atravessado pelos conflitos sociais e pela ideologia”, caso das práticas médicas e biotecnológicas, as tarefas organizativas como que "pairam" acima dos eventos "externos". Contrariamente, a saúde coletiva é toda ela atravessada pelos conflitos sociais e pela política, e as circunstâncias então vivenciadas tornavam a previsão do futuro tarefa ingrata e arriscada.

Os congressos da APSP, embora "regionais", têm a marca histórica de serem inovadores e de agregar número expressivo de participantes, não apenas de São Paulo, mas também de outros estados. Desde há muito, a APSP contava com estrutura profissional que se encarregava das operações logísticas, enquanto uma comissão organizadora específica encarregavase da programação científica e outras tarefas “acadêmicas". Também os congressos contavam com apoio das agências de fomento (Fapesp e CNPq), de numerosas secretarias municipais de saúde e da estadual, além de associações próprias do campo, como o Cosems.

Para o congresso de 2017, estas possibilidades ruíram ou tiveram a perspectiva bastante reduzida.
Assim, com uma conjuntura política desfavorável e sem condições de arcar com os custos de estrutura profissional, tivemos o desafio de nós mesmos realizarmos o processo por inteiro. Nesta primeira reunião de trabalho, portanto, expressavam-se diferentes perspectivas para o futuro do congresso. Para nós, seria impossível não o fazer, tanto quanto fazê-lo significava dar continuidade às tendências das edições anteriores e buscar novas conexões com os movimentos sociais e populares de saúde, retomando a pauta histórica da Reforma Sanitária. Um caminho que certamente passava pela política e outras formas de produção do conhecimento, e que deveria buscar formas densas de subjetividade, um adensamento também nas relações com a arte e a cultura, relações sempre presentes na saúde e, não obstante, negligenciadas.

Influenciados pela Bienal, que em novembro ainda estava instalada no Ibirapuera, a primeira categoria que emergiu foi "imaginação política", bem explicitada e suficientemente debatida ao longo dos trabalhos. Tal categoria foi "cristalizada" pela proposta do Laboratório Clínico-Político, de Suely Rolnik (Laboratório..., 2016), vivenciada por um dos autores. E foi com ela que a reunião se encerrou. A ideia da imaginação criativa e desta fertilização com a arte, significando outras possibilidades epistêmicas, instalou-se entre nós. A partir deste ponto, vimos que não poderia haver outra forma de construir o $15^{\circ}$ Congresso que não fosse por meio do invento.

As reuniões seguintes propiciaram novas "tempestades" e, em coletivos ampliados com a presença de colegas dos núcleos do interior, novas perspectivas foram se somando e tornando mais claros os contornos do que poderíamos fazer. A memória das reuniões aponta os seguintes trajetos cartográficos: congresso "para fora", na rua, peripatético, em movimento; ênfase no processo regional, com protagonismo dos núcleos; diferentes modelagens, de acordo com o potencial do lugar e a capacidade de organização e mobilização dos coletivos regionais; parcerias locais e regionais com movimentos sociais, sindicatos e trabalhadores; autofinanciamento e estímulo ao trabalho voluntário; desdobramentos de perspectivas diferenciadas, com abertura para a diversidade; desenvolvimento da solidariedade, 
buscando, desde o início, a desmercantilização das atividades. Não por acaso, desmercantilizar a saúde acabou formando um tripé com outros dois lemas: a desmedicalização e a descolonização da saúde.

Seriam então realizadas atividades de qualquer natureza e formato nos núcleos regionais - rodas de conversa, seminários, aulas abertas, intervenções, colagens, cursos -, com ou sem apresentação de trabalhos científicos ou, antes, observando as necessidades e o desejo dos ativistas ou interessados locais. Não havia um formato único, o importante seria respeitar as características da região e, importante deliberação, o processo todo seria finalizado numa celebração de tipo "congressual", que pudesse ser a síntese dos diferentes eventos parcelares do congresso, uma apoteose.

Como conduzir esta finalização, esta apoteose? Finalmente, uma matriz conceitual foi sintetizada e apresentada logo no começo de 2017. Além da categoria Imaginação Política, duas outras se apresentaram: Território e Produção do Comum. O comum já tinha feito sua inserção no $13^{\circ}$ Congresso e agora retornava com estilo. A matriz, entretanto, veio apresentar mais três categorias: Conhecimento, Técnica e Trabalho. As categorias foram então alinhadas em um quadro $3 \mathrm{X}_{3}$, formando entre elas um intricado entrelaçamento, conforme se vê no Quadro 1:

Foram concebidos espaços de discussão que deveriam articular, a cada sessão, exposições teóricopolíticas no entrecruzamento de duas categorias: Imaginação Política e Conhecimento, Territórios e Trabalho ou Produção do Comum e Técnica, e assim sucessivamente. Os expositores e demais participantes foram convidados a pensar novas possibilidades de significação contidas no espaço de referência criado, implicando um movimento de desconstrução do já pensado, com o desafio de reelaborar a fragmentação contemporânea da política e seus sistemas.

Assim, terminamos com 6 eixos conceituais, aos quais se agregaram outros 12 eixos temáticos: juventudes, sexualidades e gêneros, população preta, pobre e periférica, sociedade indígena e sociedade contemporânea, direitos e mundo do trabalho, direitos e saúde mental, organização política e participação popular na saúde, comunicação em saúde, sofrimento psicossocial e drogas, movimentos sociais, desobediência civil e rebelião, territórios e produção da saúde e gestão democrática da saúde. O Quadro 2 a seguir dá ideia do que veio a ser proposto:

\section{Quadro I - Matriz de categorias}

\begin{tabular}{|l|l|l|l|}
\hline EIXOS & CONHECIMENTO & TÉCNICA & TRABALHO \\
\hline IMAGINAÇÃO POLÍTICA & Imaginação e conhecimento & $\begin{array}{l}\text { A técnica da imaginação ou } \\
\text { imaginação como técnica }\end{array}$ & $\begin{array}{l}\text { Trabalhar (produzir) o } \\
\text { imaginário ou imaginação e } \\
\text { trabalho }\end{array}$ \\
\hline TERRITÓRIOS & $\begin{array}{l}\text { o território do conhecimento } \\
\text { ou o conhecimento como } \\
\text { território }\end{array}$ & $\begin{array}{l}\text { o território como técnica ou } \\
\text { a técnica do território }\end{array}$ & $\begin{array}{l}\text { Trabalhar (produzir) o } \\
\text { território }\end{array}$ \\
\hline PRODUÇÃO DO COMUM & $\begin{array}{l}\text { o conhecimento comum ou o } \\
\text { comum como conhecimento }\end{array}$ & $\begin{array}{l}\text { A técnica do comum ou o } \\
\text { comum da técnica }\end{array}$ & $\begin{array}{l}\text { Trabalhar (produzir) o } \\
\text { comum }\end{array}$ \\
\hline
\end{tabular}

\section{Quadro 2 - Espaços de interações grupais}

\begin{tabular}{|c|c|c|c|}
\hline & $1^{\circ} \mathrm{dia}$ & $2^{\circ} \mathrm{dia}$ & $3^{\circ} \mathrm{dia}$ \\
\hline $\begin{array}{l}\text { PROSAS E } \\
\text { NARRATIVAS }\end{array}$ & $\begin{array}{l}\text { Espaço de discussão grupal. } \\
\text { Temas definidos em função da } \\
\text { mostra/curadoria. } \\
\text { Salas dispostas com I } \\
\text { coordenador/animador da DT; } \\
\text { os participantes aderem por } \\
\text { afinidade com o tema. }\end{array}$ & $\begin{array}{l}\text { Espaço de discussão grupal. } \\
\text { Temas definidos em função da } \\
\text { mostra/curadoria. } \\
\text { Salas dispostas com I } \\
\text { coordenador/animador da DT; } \\
\text { os participantes aderem por } \\
\text { afinidade com o tema. }\end{array}$ & $\begin{array}{l}\text { Assembleia de encerramento } \\
\text { e posse da diretoria eleita, } \\
\text { biênio 2017-2019 }\end{array}$ \\
\hline
\end{tabular}


A ideia era simples. Enquanto os espaços da manhã deveriam permitir a explanação de categorias de análise em nível crítico, os espaços da tarde foram concebidos para funcionar como atividade coletiva, onde as experiências dos sujeitos pudessem contar para ressignificar vivências e produzir novos conhecimentos. Como se disse numa das ementas,

Prosas e Narrativas são espaços política e afetivamente sensíveis. [...] neles se reúnem pesquisadores, trabalhadores, estudantes e representantes de movimentos sociais para aprofundar a discussão de específico tema [...] tomam por base material derivado de investigação científica ou articulado com a experienciação de situações de vida (vida política e afetiva, de experiência sindical, relações de trabalho, movimentos sociais, relação poder/repressão etc.). Nos Espaços pensa-se a produção do conhecimento em ato, um momento de autopoiese grupal. (APSP, 2017)

Assumidos os contornos e os riscos, pusemonos em marcha. Já estávamos em marcha. Quando o congresso começa? Já começou, era a resposta!

\section{Não é que nossos congressos não tenham teses}

Poucas coisas mais podem ser ditas nestas memórias que se arrastam. Uma delas diz respeito à escolha da palavra de ordem política do congresso: há uma grande desordem sob o céu. Naturalmente, a inspiração é Mao Tsé-Tung, por intermédio de Slavoj Zizek.

Zizek (2012), discutindo a onda neoliberal que varre o mundo, com a produção de toda sorte de destruição e guerras, fome, devastação e desenraizamento de populações, situa este momento como a atualização do capitalismo contemporâneo, reflexo da superexploração combinada, tanto da força de trabalho humana como dos recursos naturais, o que nos aproximaria de uma catástrofe de proporções míticas. A forma combinada, simplificadamente, teria quatro componentes, que ele denomina "quatro cavaleiros do Apocalipse": (1) a crise ecológica, (2) as consequências da revolução biogenética, (3) os desequilíbrios do sistema, como propriedade intelectual, luta por matérias-primas, comida e água, e (4) crescimento explosivo das divisões e exclusões sociais. Tudo isto vem se traduzindo em concentração exacerbada da riqueza, fundamentalismo religioso, exclusão social disfarçada de inclusão - a forma favela, emergência e reemergência do fascismo etc.

Em outra obra, Bem-vindo ao deserto do real!, Zizek (2008) já alertava que as pessoas, por efeito da ideologia, estão mais dispostas a aceitar o fim da vida na Terra do que a derrocada do capitalismo. Mas aqui o efeito desta tremenda devastação vem acarretando perplexidade e paralisia na massa - numa notável aproximação com as posições de Negri e Hardt (2016) -, e Zizek agora acrescenta: "Vivemos um estado de negação fetichista coletiva: sabemos muito bem que alguma hora isso acontecerá, mas ainda assim não acreditamos que possa realmente acontecer". Acontecer, ou seja, a produção do Apocalipse.

Como ultrapassar esta situação de perplexidade e de negação? Pela aceitação do que está acontecendo, afirma Zizek, pela aceitação da realidade contemporânea: negar ou tentar fórmulas de conciliação pode produzir alguma ilusão de conforto, mas não afastará o problema. A única saída seria "não vermos mais as coisas como ameaças, mas como oportunidade de recomeçar”. E ele completa: "A aceitação e o entendimento do que está acontecendo pode provocar uma virada, na direção de um 'entusiasmo emancipatório', como verdade a ser vivida. Prepara-te para a batalha!" (Zizek, 2012, p. 13). Ou seja, ao invés de amaldiçoar as perversidades do céu, diga: "Há uma grande desordem sob o céu, a situação é excelente".

Foi este o grande desafio que imaginamos enfrentar com entusiasmo emancipatório, espécie de mal que progressivamente vem se instalando entre nós. Possivelmente, a verdade a ser vivida signifique não exatamente a perda de um mundo completo de direitos e conquistas, mas sim do mundo construído pelas nossas perspectivas utópicas frequentemente na forma de ilusões ("se mudarmos aqui e ali a vida talvez possa continuar como antes”).

\section{Para finalizar}

O que acontece quando palavras de ordem se transformam em multidão? Certamente, alguns poderiam imaginar possibilidades: confusão e 
caos, inexpressividade individual, alienação e comportamento amorfo e teleguiado seriam algumas delas. De verdade, poderíamos dizer que o $15^{\circ}$ Congresso Paulista de Saúde Pública expressou um pouco de cada uma dessas coisas. Todavia, este congresso expressou muito mais do que isso: expressou potência criativa, expressou vontade política, expressou a construção do comum, uma vontade comunal. De certo modo, possibilitou a emergência de novas ágoras.

Terminamos o $15^{\circ}$ congresso afetados! Foram 10 eventos ao longo de quatro meses, um em cada núcleo regional, mais a finalização apoteótica, afora o tempo anterior de preparação, discussão e vivência de angústias. Aproximadamente 4 mil participantes estiveram presentes nestas realizações, um número expressivamente maior do que a média dos congressos anteriores. Para dar uma ideia da proporção, apenas em Ribeirão Preto quase 2 mil pessoas estiveram presentes nas atividades realizadas! Além disso, envolveram-se na preparação das atividades um conjunto grande de pessoas, dando consistência e musculatura aos núcleos regionais que assim saíram fortalecidos das jornadas. Este foi um efeito dos mais notáveis e altamente positivo, o fortalecimento do ativismo e da presença sanitária no território paulista. Os formatos foram os mais diversificados, com maior ou menor presença popular, com maior ou menor expressão crítica, com rodadas sucessivas de encontros ou com apenas um evento.

Mas em todos os encontros observou-se a marca da liberdade e o enorme desejo de agir. Pensamos que não se estará distante de afirmar que fomos muito livres durante estes meses todos, desde novembro de 2016 a novembro de 2017 , porque fizemos o que julgamos ser necessário fazer, e nos manifestamos segundo, coletivamente, entendemos que deveríamos fazer.

Este foi um congresso no qual a política se fez presente, aliás como em todos os congressos, mesmo os de ciências da natureza. E com mais razão ainda quando tratamos de políticas públicas e da saúde do povo, coisas todas, como anteriormente dito, atravessadas pela política e pelos conflitos sociais. De certo modo, rompemos o silêncio e o cerco a que a atual conjuntura tenta nos forçar, seja no sistema público de saúde seja na universidade brasileira. Mesmo com a opressão crescente, faz sentido pensar a frase de Jean-Paul Sartre, escrita na República do silêncio, em 1944:

Nunca fomos mais livres do que durante a ocupação alemã. Tínhamos perdido todos os nossos direitos e, em primeiro lugar, o de falar; éramos ultrajados a cada dia e tínhamos de nos calar; éramos deportados em massa como trabalhadores, como judeus, como prisioneiros políticos; em todo lugar, nos muros, nos jornais, nas telas de cinema, reencontrávamos o semblante imundo que nossos opressores queriam nos dar de nós mesmos: por causa de tudo isso éramos livres. (Sartre, 2009, p. 1)

Pensamos que foi com este sentimento de liberdade que construímos o $15^{\circ}$ Congresso Paulista de Saúde Pública, e foi com este sentimento de liberdade que nos construímos.

\section{Referências}

\begin{abstract}
APSP - ASSOCIAÇÃO PAULISTA DE SAÚDE PÚBLICA. Mapas afetivos, territórios da comunicação e construção de redes: detalhes. 2017. Facebook. Disponível em: <https://goo.gl/ eMo6fe>. Acesso em: 21 mar. 2018.
\end{abstract}

DONNANGELO, M. C. F. A pesquisa na área da Saúde Coletiva: década de 7o. In: BUSS, P. M. (Org.). Ensino da saúde pública, medicina preventiva e social no Brasil. Rio de Janeiro: Abrasco, 1983. p. 17-35.

IANNI, A. M. Z. A política posta em questão: o sucesso do $13^{\circ}$ Congresso Paulista de Saúde Pública. Saúde e Sociedade, São Paulo, v. 24, p. 1318, 2015. Suplemento 1.

LABORATÓRIO clínico-político conduzido por Suely Rolnik: oficina de imaginação política: obra do Amilcar Packer na $32^{\text {a }}$ Bienal de São Paulo: domingo, 9 de outubro das 14 h às 17 h. Laboratório de Sensibilidades, Santos, 3 out. 2016. Disponível em: <https://goo.gl/G2V1tk>. Acesso em: 17 jan. 2018.

NEGRI, A.; HARDT, M. Declaração: isto não é um manifesto. São Paulo: N-1, 2016. 
SARTRE, J. P. A república do silêncio. Fólio:

Revista de Letras, Itapetinga, v. 1, n. 1, p. 117-120, 2009. Disponível em: <https://goo.gl/aChukL〉. Acesso em: 17 jan. 2018.
ZIZEK, S. Bem-vindo ao deserto do real! São Paulo: Boitempo, 2008.

ZIZEK, S. Vivendo no fim dos tempos. São Paulo: Boitempo, 2012.

\section{Contribuição dos autores}

Botazzo apresentou a primeira versão do manuscrito. Louvison, Akernan, Pereira, Weiller e Teixeira foram responsáveis pela revisão do texto. Todos os autores participaram do processo geral de criação, das oficinas de construção do Congresso.

Recebido: 05/12/2017

Aprovado: 29/12/2017 